\title{
The effects of signal intensity upon conditioned suppression: Effects upon responding during signals and intersignal intervals
}

\author{
HIROSHI IMADA, AKIHIKO YAMAZAKI, and MAKI MORISHITA \\ Kwansei Gakuin University, Nishinomiya, Japan
}

\begin{abstract}
Two rat experiments were run to study the effects of a wide range of signal (CS) intensities on the suppression of licking. In Experiment 1, a light CS was varied over five levels, including zero intensity. Conditioned suppression was found to vary directly with CS intensity, but basal lick rates were not different among groups. In Experiment 2, an attempt was made to disturb the basal rate of licking, while a tone CS was varied over four levels, including zero intensity. Here the suppression of the CS rates was found to be directly related and basal rates inversely related to CS intensity. The results as a whole were consistent with the Perkins-Logan hypothesis regarding the effects of CS intensity upon conditioning, but not with the Rescorla-Wagner model of classical conditioning.
\end{abstract}

The intensity of the conditioned stimulus (CS) has been regarded as one of the important variables in both classical and instrumental conditioning experiments. Although the results of these studies are somewhat equivocal (Gray, 1965), they generally support the view that the relation between CS intensity and conditioned response magnitude is positive, a phenomenon known by the Hullian name of "stimulus intensity dynamism' (Hull, 1949).

Stimulus intensity dynamism has also been reported in conditioned suppression (Kamin, 1965; Kamin \& Brimer, 1963; Kamin \& Schaub, 1963). The effects of CS intensity in an aversive conditioning situation, however, can be treated in a completely different manner, as suggested by recent developments in studies of aversive conditioning (Imada \& Soga, 1971; Nageishi \& Imada, 1974; Odling-Smee, 1975; Seligman, 1968, 1969; Weiss, 1970).

Seligman (1968), for example, had demonstrated that unsignaled shocks produce greater suppression of basal rate of leverpressing than do signaled shocks, a result he explains with his safety signal hypothesis, which assumes that rats under a signaled shock condition learn to discriminate the signal (CS), or more correctly, the signal plus background cues (BC), from the $\mathrm{BC}$ alone, and the former comes to serve as a good predictor of danger and the latter of safety. When the shocks are given unsignaled or signaled by a cue of subliminal or zero intensity, no such discrimination should be possible, and hence animals in such a situation would be persistently fearful. Viewed in this way, it becomes immediately obvious that the problem of CS intensity in an on-the-baseline condi-

The present research was supported by a grant in aid of research awarded to Hiroshi Imada by the Murao Foundation, Kobe, Japan. tioned suppression experiment can be discussed in terms of discriminability of the $\mathrm{CS}+\mathrm{BC}$ from the $\mathrm{BC}$ alone. Decreasing CS intensity, therefore, should make this discrimination difficult, and thus should lead to the suppression of baseline responding. Unfortunately, in no previous studies of conditioned suppression dealing with CS intensity, has reference been made to the basal rate of responding. Also, in previous studies that dealt with the effect of predictability of shock upon basal rates of responding in conditioned suppression situations, the CS intensities were varied only at two levels, that is, either salient or zero (cf. Seligman, Maier, \& Solomon, 1970).

The purpose of the present investigation was to study, in a licking-based conditioned suppression situation, the effects of a wide range of CS intensities upon both the baseline rate of licking and the licking during the CS. The hypothesis was that suppression of licking during the CS would be directly related to CS intensity, while suppression of basal rate of licking would be inversely related to $C S$ intensity.

Two theories are relevant to this assumption: the Perkins-Logan hypothesis regarding the effect of CS intensity upon conditioning and the Rescorla-Wagner model of classical conditioning. The Perkins-Logan hypothesis (Perkins, 1953; Logan, 1954) regards the BC as unreinforced zero-intensity stimuli, and assumes that the generalization of inhibition from this $\mathrm{BC}$ to the CSs should be greater when the CS is weak than when it is strong. It is also assumed that the excitation which CSs evoke is the same regardless of their intensity. But since response strength is regarded as a function of the value of "excitation minus inhibition," the weaker the CS, the less response strength there should be. Since this hypothesis con- 
cerned the effect of CS intensity upon the response conditioned to the $C S$, no emphasis was placed upon an undeniable possibility of generalization of excitation from the $\mathrm{CS}(+\mathrm{BC})$ to the $\mathrm{BC}$. Therefore, the weaker the $\mathrm{CS}$, the greater should be the generalization of excitation to the BC.

The Rescorla-Wagner model (e.g., Rescorla \& Wagner, 1972) also predicts a direct relation between CS intensity and suppression of a response during the $\mathrm{CS}$ and an inverse relation to suppression of a response during the $\mathrm{BC}$. But this prediction, unlike that from the Perkins-Logan hypothesis, applies only while conditioning is still in progress, as suggested by the following equations:

$$
\begin{gathered}
\mathrm{V}_{\mathrm{AX}}=\mathrm{V}_{\mathrm{A}}+\mathrm{V}_{\mathrm{X}}, \\
\Delta \mathrm{V}_{\mathrm{A}}=\alpha_{\mathrm{A}} \beta\left(\lambda-\mathrm{V}_{\mathrm{AX}}\right),
\end{gathered}
$$

and

$$
\Delta \mathrm{V}_{\mathrm{X}}=\alpha_{\mathrm{X}} \beta\left(\lambda-\mathrm{V}_{\mathrm{AX}}\right)
$$

Let the CS be represented by $\mathrm{A}$ and the $\mathrm{BC}$ by $\mathrm{X}$. The associative strength of the $\mathrm{CS}+\mathrm{BC}$, represented by $\mathrm{V}_{\mathrm{AX}}$, is assumed to be a summation of associative strength of each component, $V_{A}$ and $V_{X}$. The changes in associative strength of the respective components are represented by the equations for $\Delta V_{A}$ and $\Delta V_{X}$. Here the alphas are learning-rate parameters determined roughly by stimulus salience, and beta is another learning-rate parameter associated with the US. The $\lambda$ value represents the asymptotic level of associative strength that the US will support. With reference to the effects of CS intensity, the following deductions can be made from the equations: The stronger the CS, the greater is the value of $\alpha_{A}$ and the more rapid would be the growth of $V_{A}$. Furthermore, $X$ also gains associative strength, but the growth rate is less for $\mathrm{X}$ than for As because the value of $\alpha_{X}$ is less than any of the values of $\alpha_{A}$. The greater the value of $\alpha_{A}$, the greater will be the value of $v_{A}$ and the smaller will be the value of $V_{X}$, to the point at which the value of $V_{A X}$ reaches $\lambda$. To this stage, the predictions from both the Rescorla-Wagner model and the Perkins-Logan hypothesis coincide regarding the effects of CS intensity. It should be noted, however, that $\mathrm{X}$ is unreinforced during the intertrial intervals and hence $V_{X}$ will eventually become zero. Therefore, the value of $V_{A X}$ will become equal to the value of $V_{A}$, regardless of the $C S$ intensity. This means that no differential effects of CS intensity upon either the licking rates during the $\mathrm{CS}+\mathrm{BC}$ or during the $\mathrm{BC}$ would be expected in the final stage of training.

\section{EXPERIMENT 1}

Experiment 1 was designed and conducted because there had been no previous investigations into the ef- fects of a wide range of CS intensities upon both basal and CS rates of responding in a conditioned suppression situation, and also because of the intriguing theoretical implications of the problem described above. In this experiment, five different intensities of light, including zero intensity, were used as CSs, and the licking rate of thirsty rats both during the $\mathrm{CS}+\mathrm{BC}$ and during the $\mathrm{BC}$ alone were measured.

\section{Method}

Subjects. Sixty experimentally naive male albino rats of the Wistar strain were used as subjects. The mean body weight of these rats at the start of the experiment was approximately $252 \mathrm{~g}$ (range: 207-309 g).

Apparatus. The apparatus consisted of four identical drinking boxes that have long been used in the present writers' laboratory for conditioned suppression experiments (e.g., Yoshida, Kai, \& Imada, 1969; Imada \& Okamura, 1975; Nageishi \& Imada, 1974). Each drinking box had a grid floor and was $20 \mathrm{~cm}$ long, $10 \mathrm{~cm}$ wide, and $15 \mathrm{~cm}$ high (inside dimensions). In the lower part of the wall at one narrow end of the box was a hole (12 $\mathrm{mm}$ in diameter) through which the rat could gain access to a drinking tube. When a rat made contact with the drinking tube, a low-current circuit between the tube and the grid floor of the box was completed, which activated a contact relay located in the adjoining room. Four such boxes, each having a transparent ceiling, were placed on a table in such a way that each of the boxes was separated from the adjacent two by an equal distance and the drinking-hole wall of each faced outward from the center of the table. A fan was attached directly below the center of the table to produce a masking noise of approximately $65 \mathrm{~dB}$. A lampshade with a 100 -W electric bulb in it was suspended $163 \mathrm{~cm}$ directly above the center of the table. The $\mathrm{CS}$ in Experiment 1 was the illumination of this lamp; its source voltage was varied over five different levels by a Variac. The illumination of the apparatus during the experiment was done by indirect lighting, which shed light of $1.5 \mathrm{~lx}$ into each box. Scrambled electric shock was delivered from an ac-shock source to the grid floor through a $250-k \Omega$ current-limiting resistor in series with the rat.

All the electronic equipment for controlling and recording was placed in an adjoining room. There was no possibility for rats in the drinking boxes to hear the mechanical sounds accompanying their own licking behavior, or to hear the recordings and control apparatus. It might be noted also that, as previous experiments have shown, a rat's behavior is unaffected by the behavior of other rats being trained in different boxes on the same table.

Procedure. All rats were tamed by handling for $5 \mathrm{~min} /$ day for 5 days. Then they were put on a $50-\mathrm{min} /$ day watering schedule that was maintained throughout the experiment. The subjects were then trained to drink tap water in the drinking boxes for $5 \mathrm{~min}$ daily. After the daily training, the rats were returned to the home cage and given an opportunity to drink water for another $50 \mathrm{~min}$ there. This training of drinking was continued for 37 days. On Day 33 of this training, pretest trials were given in which a light of $6 \mathrm{sec}$ duration was presented twice, once at $100 \mathrm{sec}$ and again at $200 \mathrm{sec}$ after the beginning of the session. The source voltage of the lamp was adjusted at $100 \mathrm{~V}$, and the brightness within each box was $133 \mathrm{~lx}$. The subjects were then divided into five groups of 12 each matched on the basis of body weight, the degree of suppression to the pretest light, and the total number of licks per session on Days 34 and 35 . The mean total number of licks per session on Days 34 and 35 was approximately 1,527.

The five matched groups of rats were then assigned randomly to one of the five conditions of different CS intensities. They underwent conditioning trials on the baseline for the following 36 days, with a mean of three trials (range: $2-4$ ) per 5-min session. The groups were designated in terms of the source voltage of the lamp. For each group, the brightness of the light CS measured inside the drinking boxes is given after the hyphen: Group 0-1.5 lx (no CS condition), Group 30-2.6 lx, Group 45-8.7 lx, Group 65- 
$33 \mathrm{~lx}$, and Group 100-133 lx. It should be noted that no CS was presented to Group 0, and hence this group was run under an unsignaled shock condition. The change of brightness of Group 30 from $1.5 \mathrm{~lx}$ (room-light brightness) to $2.6 \mathrm{~lx}$ was such that a human observer carefully watching the grid-floor surface of the box could just barely perceive the change. Except for the difference in the CS intensity, the five groups were treated identically throughout the experiment.

The CS had a duration of $6 \mathrm{sec}$, and it terminated with the onset of a grid-shock US of .7 sec duration. The US intensity was gradually increased every 3 days as follows: $80,95,110$, to $140 \mathrm{~V}$. From Day 13 of conditioning and for the rest of the experiment, the US intensity was kept at $155 \mathrm{~V}$. The intersignal intervals (offsetonset intervals) varied within the range of 20 to $130 \mathrm{sec}$, with a mean of $75 \mathrm{sec}$.

\section{Results and Discussion}

The conditioning curves, in terms of mean suppression ratio (SR) for the five groups, are shown in Figure 1 in blocks of 3 days or nine trials. This SR was measured in terms of a ratio of the form $A$ / $(A+B)$, in which $A$ was the number of licks during the $\mathrm{CS}$ and $\mathrm{B}$ was the number of licks during a comparable period immediately preceding CS onset. For Group 0, to which no CS was given, A was the number of licks during the preshock period in which the CS was given to the other groups. The mean SR for all 60 rats calculated for two pretest trials was .35 . The SRs shown in Figure 1 are the group means calculated on the basis of summated values of nine $A$ and nine B periods for each subject for each block.

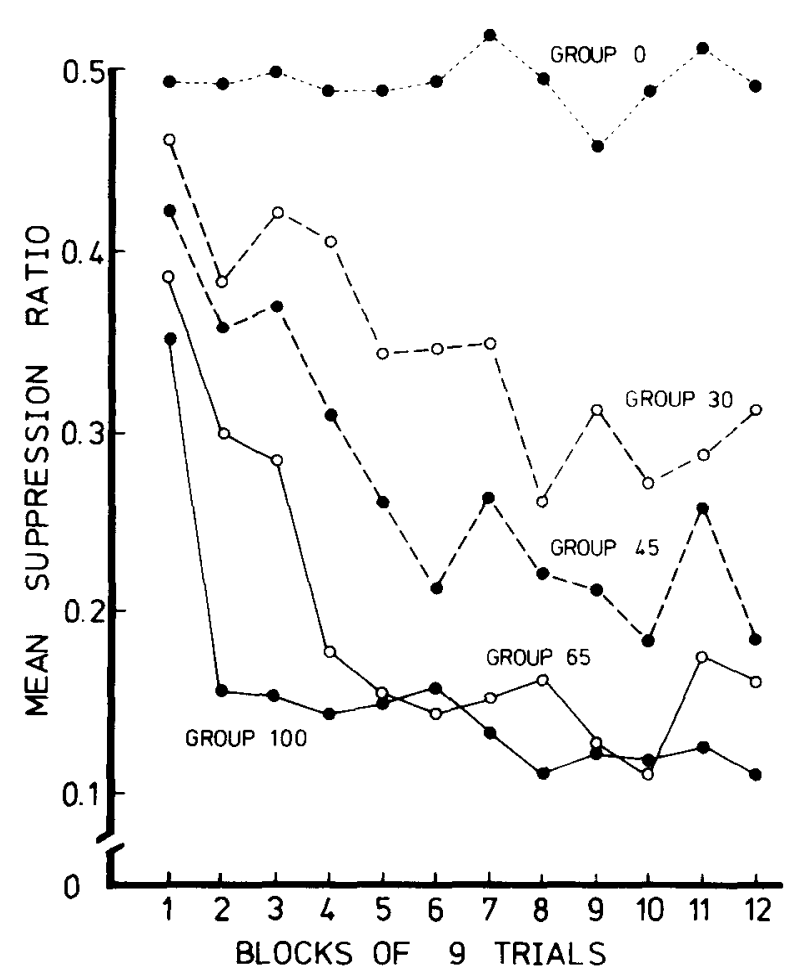

Figure 1. Mean suppression ratios of five groups in blocks of 3 conditioning days.

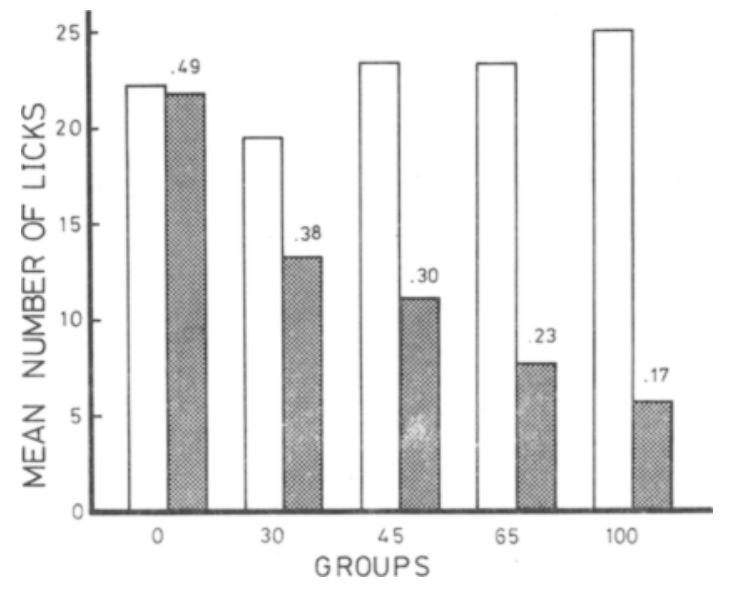

Figure 2. Mean number of licks per $6 \mathrm{sec}$ during the pre-CS (white bars) and CS (shaded bars) periods calculated for all 36 conditioning days. The numbers over the shaded bars are mean SRs calculated from individual SRs.

The following two points should be apparent from the graph: First, in all groups except Group 0, there is clear evidence of increased suppression (evidence of conditioning) over conditioning days. Second, the stronger the CS, the greater the suppression.

Figure 2 summarizes the results regarding the preCS and during-CS licking rates per $6 \mathrm{sec}$ as well as the mean overall SRs for all 36 conditioning days. ${ }^{1}$ It should be noted that the means of the number of licks during the $6 \mathrm{sec}$ preceding the CS presentation, as represented by the white bars, were relatively high and did not differ markedly among groups. Although Group 30 showed a slightly lower pre-CS level than the other groups, the differences among groups were not significant $[\mathrm{F}(4,55)=1.16]$. The differences between the overall mean SRs were statistically significant $[F(4,55)=42.55, p<.001]$ and the results of multiple $t$ tests $(\alpha=.05)$ between all possible pairs revealed that all the differences were significant.

Suppression ratios by themselves provide an incomplete description, however, since different preCS rates have some theoretical significance, as described in the introduction of the present paper. Reference has to be made to the pre-CS rates, as given in Figure 2. As is clearly shown, the positive relation between CS intensity and suppression involved only $\mathrm{CS}$ rates and not pre-CS rates. It should be remembered, however, that both CS rates and pre-CS rate changes were expected in the present study. Why did the pre-CS rates not differ among groups with different CS intensities? Unsignaled shocks generally depress baseline responding in a conditioned suppression situation, but they did not do so here. One possible reason for this failure is that shock intensity was increased over training days too gradually and was not intense enough to affect baseline responding. 
Another possibility that may have been confounded with the first is that, because of the long period of preliminary training of drinking (over 37 days), a latent-inhibition-like phenomenon may also have taken place.

The present finding is not inconsistent with the Perkins-Logan hypothesis if one assumes that the generalization of excitation (fear) from the CS $(+\mathrm{BC})$ was not large enough to affect baseline licking rates but that generalization of inhibition from the $\mathrm{BC}$ to the CSs $(+\mathrm{BC})$ was present, its amount being dependent upon the CS intensity. The present result was not consistent with the Rescorla-Wagner model in that there was no tendency for the SRs to converge to the same asymptote, each CS group appearing to have reached a separate asymptote, as Figure 1 suggests.

\section{EXPERIMENT 2}

Experiment 1 was successful in obtaining a clear positive relation between $\mathrm{CS}$ intensity and conditioned suppression under conditions of matched baseline levels of responding, thus confirming the first half of the hypothesis of the present investigation. But the second half of the hypothesis, that is, the possibility of an inverse relationship between CS intensity and suppression of basal rate of licking, was left unconfirmed. In Experiment 2, therefore, deliberate attempts were made to suppress the basal rate of licking by suddenly increasing the shock level to a high intensity at a certain stage of conditioning. Another modification made in Experiment 2 was the use of a tone CS instead of a light. As described in the procedure section of Experiment 1, the light CS of Group 30 was of such an intensity that a human observer watching the surface of the grid floor could just perceive the difference in illumination at the time of the light onset. However, the stimulus change was easily perceived by looking directly at the electric bulb. This feature of the light CS may have made the light CS of the type used in Experiment 1 weak but relatively salient even for the rat, and may have rendered the discrimination of the $\mathrm{CS}+\mathrm{BC}$ from the $\mathrm{BC}$ alone relatively easy. With a tone $\mathrm{CS}$, the source of which is not as easily localized as in the case of the electric bulb, it may become possible to administer a weak and indistinct signal.

In Experiment 2, then, the original purpose of the present study was pursued again, using the same experimental situation as in Experiment 1. This time, however, a greater emphasis was placed upon an analysis of the basal rate of licking with reference to CS (tone) salience.

\section{Method}

Subjects. Forty-four experimentally naive male albino rats of the Wistar strain were used as subjects; their mean body weight at the start of the experiment was approximately $277 \mathrm{~g}$ (range: 233-334 g).

Apparatus. The apparatus was that used in Experiment 1. In Experiment 2, the CS was a $1,000-\mathrm{Hz}$ tone presented from a speaker fixed $200 \mathrm{~cm}$ directly above the center of the table on which the drinking boxes were placed.

Procedure. The procedure for training baseline licking was exactly the same as in Experiment 1-the subjects were trained to drink water for 5 min daily over 21 days. On Day 20, a tone CS of $6 \mathrm{sec}$ duration and $85 \mathrm{~dB}$ intensity was presented twice to all subjects without being accompanied by a US. The subjects were then divided into four groups of 11 rats each matched on the basis of body weight, the degree of suppression to the pretest tones, and the final level of licking. The mean SR to the pretest tones calculated for all 44 rats was .40 , and the mean final level of drinking was 1,511 licks/5-min session. After being assigned randomly to one of the four conditions of tone intensity, the four matched groups underwent conditioning trials on the baseline over the following 18 days. The groups were designated in terms of the approximate sound level increase, in decibels, produced by the tone above the 65-dB masking noise. They were Group 0 (no CS condition), Group 1, Group 5, and Group 20. Sound levels were measured inside the drinking box by a sound-level meter (Rion, Model NA-20), "C" setting. The tone for Group 1 was just audible to the experimenters. The four groups were otherwise treated exactly the same.

The CS had a duration of $6 \mathrm{sec}$ and terminated with the onset of grid shock, which lasted $.7 \mathrm{sec}$, as in Experiment 1. The US intensity was gradually increased every 3 days as follows: 80,95 , 110 , and $125 \mathrm{~V}$. Shock intensity was changed to $155 \mathrm{~V}$ on Day 13 of conditioning and was kept unchanged for the remainder of the experiment. Ranges and means of the number of trials per day were exactly the same as in Experiment 1 . Ranges and means of the intersignal intervals were the same as in Experiment 1 from Day 1 to Day 12, but the minimum intersignal interval was changed from 20 to $10 \mathrm{sec}$ after Day 13 to increase the temporal unpredictability of shock (Nageishi \& Imada, 1974).

\section{Results and Discussion}

Only after Day 13 , that is, after the shock intensity was increased to $155 \mathrm{~V}$, did group differences become pronounced. The means of the basal rate of licking per session for Days 13-18 were 113.1, 318.3, 584.3 , and 672.9 for Groups $0,1,5$, and 20 , respectively. The weaker the CS intensity, the lower was the basal rate of licking, and an analysis of variance revealed that the groups differed significantly $[F(3,40)$ $=5.63, p<.005]$. Multiple $t$ tests revealed that Group 0 differed significantly from Groups 5 and 20 , and that Group 1 differed from Group 20. It was, therefore, clearly shown that the suppression of the basal rate of licking was inversely related to CS intensity. Why this effect was found in Experiment 2 and not in Experiment 1 is not entirely clear. It might be due to the change in the way shock intensity was increased over days or to the change in CS modality, from light to tone.

Table 1 shows the mean number of licks per $6 \mathrm{sec}$ during the pre-CS and CS periods calculated for three different spans of days. Generally, the results are in line with the hypothesis of the present study. For Days 7-18, for which the data seem to be least affected by both a ceiling effect for the pre-CS rates and by a floor effect for the CS rates, the pre-CS rates 
Table 1

Mean Number of Licks per 6 Sec During the Pre-CS (P) and CS (D) Periods Calculated for the Four Groups for Three Different Spans of Days

\begin{tabular}{|c|c|c|c|c|c|c|}
\hline \multirow[b]{2}{*}{ Days } & & \multicolumn{4}{|c|}{ Group } & \multirow[b]{2}{*}{$F(3,40)$} \\
\hline & & 0 & 1 & 5 & 20 & \\
\hline \multirow{2}{*}{$1-18$} & $\mathbf{P}$ & 14.58 & 17.01 & 20.71 & 21.73 & $2.38 \dagger \dagger$ \\
\hline & D & 14.38 & 8.76 & 5.91 & 5.12 & $8.60^{*}$ \\
\hline \multirow{2}{*}{$7-18$} & $\mathbf{P}$ & 10.20 & 13.84 & 17.35 & 18.49 & $2.88 \dagger$ \\
\hline & D & 9.96 & 5.23 & 2.72 & 2.84 & $8.05^{*}$ \\
\hline \multirow{2}{*}{$13-18$} & $\mathbf{P}$ & 2.47 & 6.58 & 11.44 & 11.72 & $4.54 * *$ \\
\hline & D & 2.74 & 1.74 & 1.09 & 1.49 & $1.42+\dagger$ \\
\hline
\end{tabular}

increased and the CS rates decreased, both significantly, with an increase of the CS intensity. These relationships are also shown graphically in Figure 3. Differences among the overall mean SRs were significant $[F(3,40)=48.19, p<.001]$, and the results of multiple $t$ tests between groups revealed that Groups 0 and 1 differed significantly from all the other groups and between each other.

A remark should be made regarding the effect of including Group 0 in the statistical tests of significance in Table 1 . The results of multiple $t$ tests revealed that Group 0 differed significantly from two or more of the other groups, but that Groups 1, 5, and 20 did not differ significantly from each other. Marginally significant were the differences in the preCS rates between Groups 1 and 20 for Days 13-18 (just short of the $5 \%$ level of significance by .2 lick/ $6 \mathrm{sec}$ ) and in the CS rates between the same pair of groups for Days 1-18 (short of significance by .4 lick/ $6 \mathrm{sec})$. It should be remembered, however, that the basal rates of licking, the pre-CS rates, were shown to be significantly different between Groups 1 and 20 for Days 13-18.

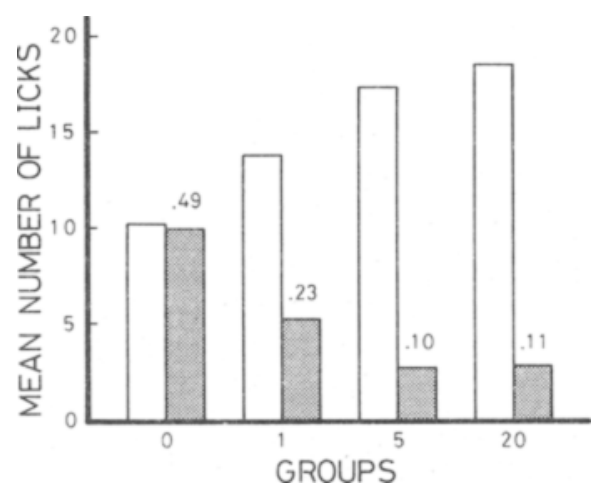

Figure 3. Mean number of licks per 6 sec during the pre-CS (white bars) and CS (shaded bars) periods calculated for Days 7-18. The numbers over the shaded bars are mean SRs calculated from individual SRs.

\section{GENERAL DISCUSSION}

Both experiments demonstrated that conditioned suppression increased (i.e., SRs decreased) as CS intensity increased, thus confirming the experimental findings summarized by Kamin (1965). It should be emphasized, however, that the nature of the data producing the above relation was completely different in the two experiments. In Experiment 1, the relationship between CS intensity and SR was due entirely to differences in CS lick rates, whereas in Experiment 2 the same summary relationship was due either to differences just in pre-CS rates (Days 13-18) or to differences in both CS and pre-CS rates (Days 7-18). The theoretical implications of these different patterns, which are completely concealed by analyses in terms of SRs alone, should not be ignored.

With regard to the relevance of the present findings to the Perkins-Logan hypothesis and the RescorlaWagner model, the data as a whole seem to be more in line with the former than with the latter. The finding that is contradictory to the Rescorla-Wagner model is that, in Experiment 1, asymptotic levels of suppression to the CS differed among groups given different CS intensities (see Figure 1). As stated earlier, this model assumes that the associative strength of the CS should finally reach the value of $\lambda$, thus indicating that the asymptotic level of conditioned suppression should be the same regardless of CS intensity. Since extended training was given in Experiment 1 , the differences in asymptotes of conditioned suppression observed among groups are contradictory to what the Rescorla-Wagner model would predict.

One might argue, however, that the similar and low CS rates in all groups for Days 13-18 in Experiment 2 , shown in Table 1 , actually suggest the same asymptote for all groups of different CS intensities. But the Rescorla-Wagner model also assumes that when the associative strength of the CS reaches $\lambda$, the associative strength of the $\mathrm{BC}$ should be zero asymptotically, and hence all groups, excepting Group 0, should show no suppression in the presence of the BC (see Odling-Smee, 1975, pp. 206-207 and pp. 208-209). However, the suppression of the basal rates of licking of Groups 1, 5, and 20 was still remarkable and significantly different among groups for Days 13-18 in Experiment 2. To obtain a better index of asymptotes, we calculated the mean basal rates for the very last 3 days (Days 16-18). They were found to be even lower than for Days 13-18. For Groups 1, 5, and 20, the mean basal rates per day were $266.6,621.0$, and 596.1 , respectively. This finding regarding the different basal rates of licking among groups at the final stage of training, when suppression to CSs was complete, is not consistent with the Rescorla-Wagner model. 
The Perkins-Logan hypothesis, on the other hand, does not contradict any aspect of the present results, providing some assumptions are made regarding such effects as ceiling and floor effects. Further experiments are warranted in this old, but new, area of research. Discussing the present results in more cognitive terms, such as "vigilance" as related to performance, may also be of interest.

\section{REFERENCES}

GraY, J. A. Stimulus intensity dynamism. Psychological Bulletin, $1965,63,180-196$.

HuLl, C. L. Stimulus intensity dynamism (V) and stimulus generalization. Psychological Review, 1949, 56, 67-76.

IMADA, H., \& OKAMURA, M. Some cues rats can use as predictors of danger and safety. Animal Learning \& Behavior, 1975, 3, 221-225.

ImADA, H., \& SogA, M. The CER and BEL as a function of predictability and escapability of an electric shock. Japanese Psychological Research, 1971, 13, 115-122.

Kamin, L. J. Temporal and intensity characteristics of the conditioned stimulus. In W. F. Prokasy (Ed.), Classical conditioning. New York: Appleton-Century-Crofts, 1965.

Kamin, L. J., \& Brimer, C. J. The effects of intensity of conditioned and unconditioned stimuli on a conditioned emotional response. Canadian Journal of Psychology, 1963, 17, 194-198.

Kamin, L. J., \& Schaub, R. E. Effects of conditioned stimulus intensity on the conditioned emotional response. Journal of Comparative and Physiological Psychology, 1963, 56, 502-507.

LogAN, F. A. A note on stimulus intensity dynamism (V). Psychological Review, 1954, 61, 77-80.

NAGEISHI, Y., \& ImadA, H. Suppression of licking behavior in rats as a function of predictability of shock and probability of conditioned-stimulus-shock pairings. Journal of Comparative and Physiological Psychology, 1974, 87, 1165-1173.

Odling-Smee, F. J. The role of background stimuli during
Pavlovian conditioning. Quarterly Journal of Experimental Psychology, 1975, 27, 201-209.

Perkins, C. C., JR. The relation between conditioned stimulus intensity and response strength. Journal of Experimental Psychology, 1953, 46, 225-231.

Rescorla, R. A., \& Wagner, A. R. A theory of Pavlovian conditioning: Variations in the effectiveness of reinforcement and nonreinforcement. In A. H. Black \& W. F. Prokasy (Eds.), Classical conditioning II: Current theory and research. New York: Appleton-Century-Crofts, 1972.

Seligman, M. E. P. Chronic fear produced by unpredictable electric shock. Journal of Comparative and Physiological Psychology, 1968, 66, 402-411.

Seligman, M. E. P. Control group and conditioning: A comment on operationism. Psychological Review, 1969, 76, 484-491.

Seligman, M. E. P., Maier, S. F., \& Solomon, R. L. Unpredictable and uncontrollable aversive events. In F. R. Brush (Ed.), A versive conditioning and learning. New York: Academic Press, 1970.

WEIss, J. M. Somatic effects of predictable and unpredictable shock. Psychosomatic Medicine, 1970, 32, 397-408.

YoshidA, T., KaI, M., \& IMADA, H. A methodological study of CER in rats with "licking" as the criterion response. Japanese Psychological Research, 1969, 11, 66-75.

\section{NOTE}

1. In calculating mean overall SRs, a single SR was calculated for each subject over all conditioning days, and the mean for each group was calculated. The reason for drawing Figure 2 on the basis of the data averaged over all 36 conditioning days was to obtain stable results. The general picture of the results for the last 18 days of conditioning did not differ essentially from that of Figure 2, although the heights of both white and shaded bars were uniformly lower by 3 to 5 licks.

(Received for publication September 24, 1980; revision accepted January 16,1981 .) 